\title{
Multicenter Study of the Hemorrhage Risk after Endoscopic Mucosal Resection Associated with Direct Oral Anticoagulants
}

\author{
Ritsu Yasuda, ${ }^{1}$ Naohisa Yoshida $\left(\mathbb{D},{ }^{1}\right.$ Takaaki Murakami $\left(\mathbb{D},{ }^{2}\right.$ Ryohei Hirose ${ }^{(D)},{ }^{1}$ Ken Inoue, \\ Osamu Dohi ${ }^{\mathbb{D}},{ }^{1}$ Yuji Naito, ${ }^{1}$ Yutaka Inada, ${ }^{3}$ Takashi Okuda, ${ }^{4}$ Daisuke Hasegawa, \\ Kotaro Okuda, ${ }^{6}$ Kiyoshi Ogiso $\mathbb{D},{ }^{7}$ Yoshikazu Inagaki, ${ }^{8}$ Koichi Soga $\mathbb{D},{ }^{8}$ Akira Tomie, ${ }^{9}$ \\ and Yoshito Itoh ${ }^{1}$
}

${ }^{1}$ Department of Molecular Gastroenterology and Hepatology, Kyoto Prefectural University of Medicine, Graduate School of Medical Science, Kyoto, Japan

${ }^{2}$ Department of Gastroenterology, JCHO Kyoto Kuramaguchi Medical Center, Kyoto, Japan

${ }^{3}$ Department of Gastroenterology, North Medical Center Kyoto Prefectural University of Medicine, Kyoto, Japan

${ }^{4}$ Department of Gastroenterology, Fukuchiyama City Hospital, Kyoto, Japan

${ }^{5}$ Department of Gastroenterology, Ayabe City Hospital, Kyoto, Japan

${ }^{6}$ Department of Gastroenterology, Kyoto Kujo Hospital, Kyoto, Japan

${ }^{7}$ Department of Gastroenterology, Osaka General Hospital of West Japan Railway Company, Osaka, Japan

${ }^{8}$ Department of Gastroenterology, Nishijin Hospital, Kyoto, Japan

${ }^{9}$ Department of Gastroenterology, Kyoto Yamashiro General Medical Center, Kyoto, Japan

Correspondence should be addressed to Naohisa Yoshida; naohisa@koto.kpu-m.ac.jp

Received 12 June 2019; Revised 7 November 2019; Accepted 28 November 2019; Published 18 December 2019

Academic Editor: Francesco Selvaggi

Copyright (c) 2019 Ritsu Yasuda et al. This is an open access article distributed under the Creative Commons Attribution License, which permits unrestricted use, distribution, and reproduction in any medium, provided the original work is properly cited.

\begin{abstract}
Backgrounds and Aims. Recently, direct oral anticoagulants (DOACs) have become widely used for preventing thromboembolism. However, postoperative hemorrhage $(\mathrm{POH})$ is a major complication associated with endoscopic mucosal resection (EMR) for colorectal lesions. In this multicenter study, we analyzed the incidence of POH after EMR associated with DOACs and explored the associated risk factors. Materials and Methods. This study was a multicenter retrospective cohort study conducted at 8 Japanese institutions. A total of 2062 cases that underwent EMR for colorectal lesions at these 8 institutions from October 2016 to September 2017 were analyzed. The cases were divided into 4 groups: the DOAC group (63 cases), warfarin group ( 34 cases), antiplatelet group (185 cases), and no antithrombotics group (1780 cases). In all lesions of the DOAC and warfarin groups, endoscopic clipping was performed after EMR. The rate of $\mathrm{POH}$ in the DOAC group, patients' clinical characteristics, the risk factors of $\mathrm{POH}$, and the rate of thromboembolism due to stopping DOACs were compared with other groups. Results. The rates of POH were $7.9 \%^{*}(5 / 63), 2.9 \%(1 / 34), 3.2 \%(6 / 185)$, and $0.6 \%^{* *}(11 / 1780)$ in the DOAC, warfarin, antiplatelet, and no antithrombotics groups, respectively (* vs. $\left.{ }^{* *}, p<0.001\right)$. Regarding risk factors, the tumor size with POH (mm) was significantly bigger than that without $\mathrm{POH}(16.2 \pm 8.3$ vs. $7.2 \pm 4.9, p<0.001)$. There were no significant differences in the rates of $\mathrm{POH}$ based on the type of DOAC. In addition, no thromboembolisms occurred due to stopping of DOAC treatment. Conclusions. Patients receiving DOACs had significantly higher rates of $\mathrm{POH}$ after EMR than those without antithrombotics.
\end{abstract}

\section{Introduction}

With the growing elderly population, the number of patients receiving antithrombotics is increasing globally [1]. Similarly, rates of colorectal neoplasia, such as colorectal cancer and colorectal adenoma, are increasing due to the aging of the population [2]. Endoscopic mucosal resection (EMR) for removing colorectal neoplasia is widely performed worldwide [3]. Concurrently, the number of patients receiving antithrombotics is increasing along with the age at which 
colonoscopic examinations are performed [4]. Physicians should therefore be familiar with performing EMR in patients receiving these drugs.

Direct oral anticoagulants (DOACs) are antithrombotic drugs that have been used to prevent cerebrovascular disease and deep vein thrombosis for about a decade [5]. In 2018, four types of DOACs (dabigatran, rivaroxaban, apixaban, and edoxaban) were approved for use in Japan. Compared with warfarin, DOACs have superior pharmacological properties, including (i) a better and rapid dose response, (ii) less difference in anticoagulant activity between individuals, (iii) no influence by vitamin $\mathrm{K}$ intake, and (iv) very few drug interactions. However, the risk of nonprocedural-related gastrointestinal (GI) bleeding is higher with some DOACs than with warfarin [6].

Postoperative hemorrhage $(\mathrm{POH})$ is a major complication associated with EMR for colorectal neoplasms, and the risk of $\mathrm{POH}$ is reportedly increased in patients receiving antithrombotics compared with those not receiving antithrombotics [7, 8]. Management of antithrombotics, including DOACs, in patients undergoing endoscopic procedures has become an important issue and was described in the guidelines of the American Society for Gastrointestinal Endoscopy (ASGE), the European Society of Gastrointestinal Endoscopy (ESGE), the British Society for Gastroenterology (BSGE), and the Japan Gastroenterological Endoscopy Society (JGES) [9-12]. However, few large-scale studies have evaluated the risk of $\mathrm{POH}$ after EMR in patients taking four types of DOACs. In addition, there is a distinct lack of multicenter studies investigating $\mathrm{POH}$ in patients undergoing EMR.

In the present study, we analyzed the rate of $\mathrm{POH}$ after EMR associated with DOACs and evaluated the associated risk factors.

\section{Materials and Methods}

This study was a multicenter retrospective cohort study conducted at eight Japanese institutions: Kyoto Prefectural University of Medicine, North Medical Center Kyoto Prefectural University of Medicine, Fukuchiyama City Hospital, Ayabe City Hospital, Kyoto Kujo Hospital, Osaka General Hospital of West Japan Railway Company, Nishijin Hospital, and Kyoto Yamashiro General Medical Center. A total of 2062 cases that underwent EMR for colorectal neoplasms at these 8 institutions from October 2016 to September 2017 were analyzed.

The cases were divided into 4 groups: the DOAC group (63 cases), warfarin group (34 cases), antiplatelet group (185 cases), and no antithrombotics group (1780 cases) (Figure 1). The DOAC and warfarin groups included cases with coprescription of antiplatelets. All lesions in the DOAC and warfarin groups received endoscopic clipping after EMR. In the other two groups, endoscopic clipping was performed according to the operator's decision.

The rate of $\mathrm{POH}$, clinical characteristics, and thromboembolic events were compared among the four groups. In addition, lesions with $\mathrm{POH}$ were compared to those without $\mathrm{POH}$ in order to analyze the risk factors of $\mathrm{POH}$ in DOAC cases. Furthermore, in the DOAC group, the rates of $\mathrm{POH}$ were calculated for each specific DOAC.

$\mathrm{POH}$ was defined when the hemoglobin level decreased by $>2 \mathrm{~g} / \mathrm{dL}$ or in cases of apparent bleeding or massive melena within 1 month after EMR [13]. A thromboembolic event was defined as the occurrence of acute coronary syndrome, stroke, pulmonary embolism, or deep vein thrombosis from one week before EMR to one month after EMR.

The management of antithrombotics was performed according to the Japan Gastroenterological Endoscopy Society guidelines for gastrointestinal endoscopy for patients taking antithrombotics in 2012 [11]. In detail, DOACs were discontinued one day before EMR, and their readministration was performed in the morning on the day after EMR. Heparin bridging was not regularly performed. Warfarin was replaced with heparin three to five days before EMR, and intravenous infusion of heparin was suspended at least three hours before EMR. Administration of both warfarin and heparin was resumed the day after EMR. Heparin was discontinued when the prothrombin time-international normalized ratio (PTINR) returned to the therapeutic range. Some patients receiving aspirin monotherapy had their treatment withdrawn for three to five days before EMR, although others did not have it withdrawn due to a high risk of thromboembolism. Thienopyridine derivatives (ticlopidine, clopidogrel, and prasugrel) were withdrawn for five to seven days. Other antiplatelets (cilostazol, ethyl icosapentate, sarpogrelate, beraprost, and limaprost alfadex) were withdrawn for one day. Administration of antiplatelets was resumed the day after EMR.

The polyp locations were divided into three parts: the rightsided colon (from the cecum to the transverse colon), left-sided colon (from the descending colon to the sigmoid colon), and rectum. Morphologically, the polyps were divided into polypoid and nonpolypoid lesions according to the Paris classification [14]. The specimens resected by EMR were placed in formalin as en bloc tissue after resection. The specimens (hematoxylin and eosin staining) were evaluated by authorized pathologists. The histopathological diagnosis was according to Japanese Scosiety of Cancer of the Colon and and Rectum (JSCCR). Especially, sessile serrated adenoma and polyp (SSA/P) was distinguished from hyperplastic polyp according to the JSCCR criteria, as follows: (1) dilatation of ducts, (2) irregularly branched ducts, and (3) horizontally arranged basal ducts (inverted T shape or L shape) [15]. SSA/Ps were diagnosed when at least $10 \%$ of the lesions had 2 of these 3 findings. Cases of mild and moderate dysplasia were diagnosed as adenoma, while cases with severe dysplasia and intramucosal cancer were diagnosed as high-grade dysplasia (HGD). A negative margin was defined when a lesion gland and cells were not detected on the definite resected margin.

2.1. EMR. The patient's bowels were prepared by the consumption of $1.0 \mathrm{~L}$ of highly concentrated polyethylene glycol solution (EA Pharma Co., Tokyo, Japan) or 2.0 L of polyethylene glycol solution the morning before the examination [16]. We used a lower GI endoscope with a single channel. For the injection solution, we used saline or $0.13 \%$ HA solution. The $0.13 \%$ HA solution was prepared by diluting $0.4 \%$ HA solution (Mucoup, Johnson \& Johnson, Tokyo, Japan, 


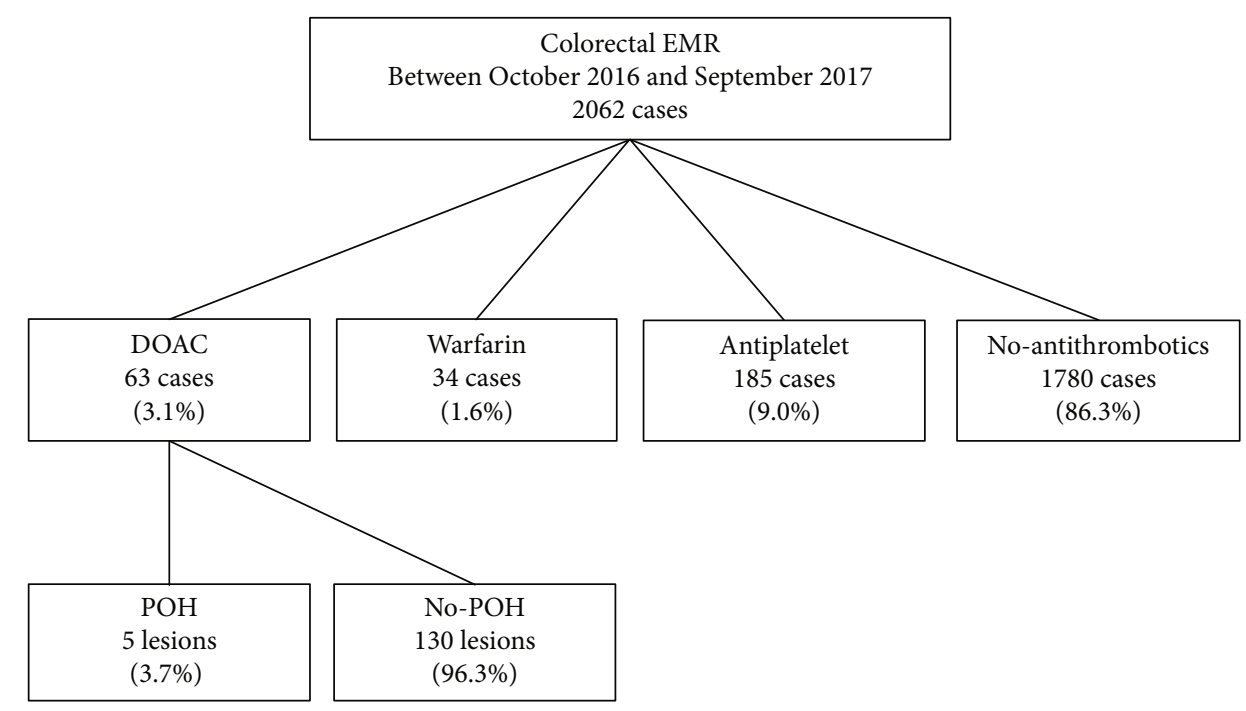

Figure 1: Study flow.

or Seikagaku Corporation, Tokyo, Japan) with NS [17]. Various snares $15-25 \mathrm{~mm}$ in size were used with an automatically controlled high-frequency generator (VIO300D or ICC200, Erbe Elektromedizin Ltd., Tübingen, Germany, or ESG100, Olympus Co., Tokyo, Japan).

2.2. Statistical Analyses. Statistical analyses were performed using the Mann-Whitney $U$ test and a one-way analysis of variance (ANOVA). Continuous variables, such as the patient age and tumor size, were analyzed using the MannWhitney $U$ test. Categorical variables, such as the rate of $\mathrm{POH}$ and other endpoints, were analyzed using a one-way ANOVA. Statistical analyses were performed using the GraphPad Prism software program (ver. 6.0; GraphPad Software, La Jolla, CA, USA). $p$ values less than 0.05 were considered statistically significant.

\section{Results}

In the DOAC, warfarin, antiplatelet, and no antithrombotics groups, the mean ages were $74.2 \pm 7.0^{*}, 73.2 \pm 6.7^{*}, 72.1 \pm$ $8.8^{*}$, and $66.3 \pm 11.1^{* *}$ years old ( ${ }^{*}$ vs. $\left.{ }^{* *}, p<0.001\right)$, and the rates of male gender were $66.7 \%(42 / 63), 67.6 \%(23 / 34)$, $75.1 \%{ }^{*}(139 / 185)$, and $61.8 \%{ }^{* *}(1100 / 1780)$ ( $^{*}$ vs. ${ }^{* *}, p<$ 0.001 ), respectively (Table 1 ). There were no significant differences in the mean polyp size or rate of right-sided colon among the four groups. In the DOAC group, the proportions of each DOAC (rivaroxaban, apixaban, edoxaban, and dabigatran) were $44.4 \%$ (28/63), 25.4\% (16/63), 19.0\% (12/63), and $11.1 \%(7 / 63)$, respectively. In the antiplatelet group, the rate of single-agent use was $80.0 \%$ (148/185), two-drug combination was $18.9 \%(35 / 185)$, and three-drug combination was $0.1 \%(2 / 185)$. Regarding the type of antiplatelet agent, there were 105 cases using aspirin, 39 cases using thienopyridine derivatives, and 63 cases using other antiplatelet agents.

In the DOAC group, lesions with and without $\mathrm{POH}$ were compared (Table 2). There were no significant differences in the morphology, tumor location, histology, or coprescription of antiplatelets between the two subgroups. However, a sig- nificant difference in the polyp size was observed between lesions with and without $\mathrm{POH}(16.2 \pm 8.3 \mathrm{~mm}$ vs. $7.2 \pm 4.9$ $\mathrm{mm}$, respectively; $p<0.001)$.

The total rate of $\mathrm{POH}$ for all cases was $1.1 \%(23 / 2062)$. The rates of $\mathrm{POH}$ were $7.9 \% *$ (5/63), $2.9 \%$ (1/34), 3.2\%** $(6 / 185)$, and $0.6 \%^{* *}(11 / 1780)$ in the DOAC, warfarin, antiplatelet, and no antithrombotics groups, respectively ( ${ }^{*}$ vs. ${ }^{* * *}, p<0.001,{ }^{* *}$ vs. ${ }^{* * *}, p=0.001$ ) (Figure 2 ). No thromboembolic events were observed in any group. Regarding the types of DOACs, we analyzed the rates of $\mathrm{POH}$ per lesion. The overall rate was $3.7 \%(5 / 135,95 \% \mathrm{CI}$ : 1.21-8.43) and the rates for each DOAC were $3.5 \%(2 / 57$, 95\% CI: 0.4-12.1), 5.7\% (2/35, 95\% CI: 0.7-19.1), 0\% (0/29, 95\% CI: $0-11.9)$, and $7.1 \%(1 / 14,95 \% \mathrm{CI}: 0.18-33.8)$ in the rivaroxaban, apixaban, edoxaban, and dabigatran users, respectively ( $p=0.602$ ) (Figure 3 ).

The details of the five patients receiving DOAC with $\mathrm{POH}$ are summarized in Table 3. Regarding the tumor size, 3 of them were $\geq 20 \mathrm{~mm}$. There were no cases with coprescription of antiplatelets. POH occurred 1 to 10 days after EMR, and 2 cases experienced POH twice (Figure 4).

\section{Discussion}

In this multicenter study, the rate of $\mathrm{POH}$ after EMR in the DOAC group was $7.9 \%$, which was significantly higher than the no antithrombotics group. A larger tumor size especially $\geq 20 \mathrm{~mm}$ was deemed a risk factor of $\mathrm{POH}$ in patients with DOAC.

Singh et al. reported that the rate of $\mathrm{POH}$ after polypectomy for colorectal neoplasia was significantly higher in patients taking clopidogrel than patients without it [18]. Pan et al. reported that the rate of $\mathrm{POH}$ after therapeutic colonoscopy for colorectal neoplasia in patients receiving low-dose aspirin was significantly higher than in patients not receiving low-dose aspirin, with an odds ratio of 6.72 (95\% confidence interval: 1.8-25.7) [19]. Regarding tumor size, Metz et al. reported that aspirin use was an independent risk factor of $\mathrm{POH}$ after EMR for colorectal lesions $\geq 20 \mathrm{~mm}$ in size, with 
TABle 1: Clinical characteristics of patients receiving endoscopic mucosal resection in the DOAC, warfarin, antiplatelet, and no antithrombotics groups.

\begin{tabular}{|c|c|c|c|c|c|}
\hline & Total & $\begin{array}{l}\text { DOAC } \\
\text { group }\end{array}$ & $\begin{array}{c}\text { Warfarin } \\
\text { group }\end{array}$ & $\begin{array}{l}\text { Antiplatelet } \\
\text { group }\end{array}$ & $\begin{array}{l}\text { No antithrombotics } \\
\text { group }\end{array}$ \\
\hline Case number & 2062 & 63 & 34 & 185 & 1780 \\
\hline Age (years), mean \pm SD (range, min-max) & $\begin{array}{l}67.2 \pm 11.0 \\
(20-93)\end{array}$ & $\begin{array}{l}74.2 \pm 7.0^{*} \\
\quad(57-88)\end{array}$ & $\begin{array}{c}73.2 \pm 6.7^{*} \\
(52-86)\end{array}$ & $\begin{array}{l}72.1 \pm 8.8^{*} \\
\quad(41-93)\end{array}$ & $\begin{array}{l}66.3 \pm 11.1 \\
(20-93)\end{array}$ \\
\hline Sex: M/F $(\%(n))$ & $\begin{array}{c}63.2 / 36.8 \\
(1304 / 758)\end{array}$ & $\begin{array}{c}66.7 / 33.3 \\
(42 / 21)\end{array}$ & $\begin{array}{c}67.6 / 32.4 \\
(23 / 11)\end{array}$ & $\begin{array}{c}75.1 / 24.9^{*} \\
(139 / 46)\end{array}$ & $\begin{array}{c}61.8 / 38.2 \\
(1100 / 680)\end{array}$ \\
\hline Mean polyp size $(\mathrm{mm})$, mean $\pm \mathrm{SD}$ (range, $\min$ - $\max )$ & $\begin{array}{l}7.4 \pm 4.6 \\
(3-30)\end{array}$ & $\begin{array}{c}7.5 \pm 5.3 \\
(3-30)\end{array}$ & $\begin{array}{l}7.6 \pm 4.3 \\
(3-20)\end{array}$ & $\begin{array}{c}7.4 \pm 3.4 \\
(3-18)\end{array}$ & $\begin{array}{c}7.1 \pm 3.9 \\
(3-18)\end{array}$ \\
\hline Rate of right-sided colon (\%) & $\begin{array}{c}51.8 \\
(132 / 255)\end{array}$ & $\begin{array}{c}48.1 \\
(65 / 135)\end{array}$ & $\begin{array}{c}41.2 \\
(7 / 17)\end{array}$ & $\begin{array}{c}48.1 \\
(25 / 52)\end{array}$ & $\begin{array}{c}68.6 \\
(35 / 51)\end{array}$ \\
\hline Coprescription of antiplatelet $(\%(n))$ & N/A & $17.5(11)$ & $23.5(8)$ & $\mathrm{N} / \mathrm{A}$ & $\mathrm{N} / \mathrm{A}$ \\
\hline
\end{tabular}

*vs. no antithrombotics group: $p<0.001$. DOAC: direct oral anticoagulant; M: male; F: female; min: minimum; max: maximum; right-sided: cecum to transverse colon; N/A: not applicable.

TABLE 2: The comparison between cases with and without $\mathrm{POH}$ after endoscopic mucosal resection in patients with DOACs.

\begin{tabular}{lccc}
\hline & DOAC users POH & DOAC users No POH & 130 \\
\hline Lesion number & 5 & $86.2(112) / 13.8(18)$ \\
Morphology $\%(n))$ & $80.0(4) / 20.0(1)$ & $7.2 \pm 4.9(3-30)$ & 0.69 \\
Polypoid/nonpolypoid & $16.2 \pm 8.3(4-25)$ & $4.6(6)$ & $<0.001$ \\
Tumor size (mm), mean (range, min-max) & $60.0(3)$ & $48.5 / 42.3 / 9.2$ & $(63 / 55 / 12)$ \\
Rate of size $\geq 20$ mm $(\%(n))$ & $60.0 / 20.0 / 20.0$ & $3.8 / 83.8 / 7.7 / 2.3 / 2.3$ \\
Tumor location $(\%(n))$ & $(3 / 1 / 1)$ & $(5 / 109 / 10 / 3 / 3)$ & 0.52 \\
Right-sided/left-sided/rectum & $0 / 40.0 / 60.0 / 0 / 0$ & $14.6(19)$ \\
Histology $\%(n)$ ) & $(0 / 2 / 3 / 0 / 0)$ & 0.37 \\
(SSAP/Ad/HGD/T1/others) & $0(0)$ & 0.35 \\
Coprescription of antiplatelet $(\%(n))$ & &
\end{tabular}

DOAC: direct oral anticoagulant; POH: postoperative hemorrhage; min: minimum; max: maximum; right-sided: cecum to transverse colon; left-sided: descending colon to sigmoid colon; SSAP: sessile serrated adenoma and polyp; Ad: low-grade adenoma; HGD: high-grade dysplasia.

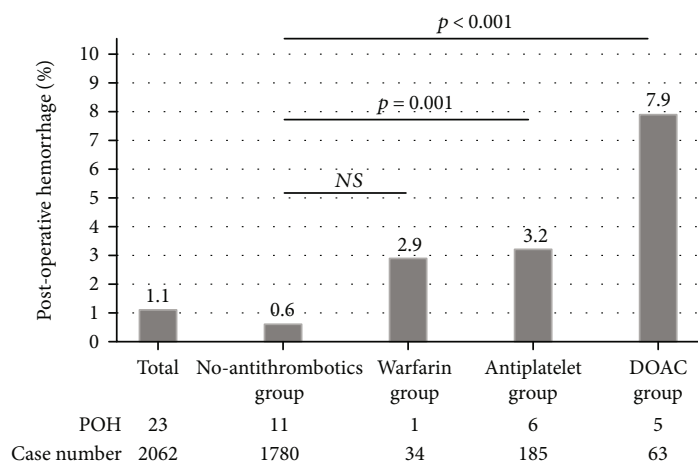

Figure 2: The rates of postoperative hemorrhage after endoscopic mucosal resection in the no antithrombotics, warfarin, antiplatelet, and DOAC groups.

an odds ratio of 6.3 [20]. Regarding anticoagulants, Hui et al. reported that warfarin use was an independent risk factor for EMR with an odds ratio of 13.37 (95\% confidence interval: 4.10-43.65) [21]. In addition, we previously reported that anticoagulant use (warfarin and DOACs) was an indepen-

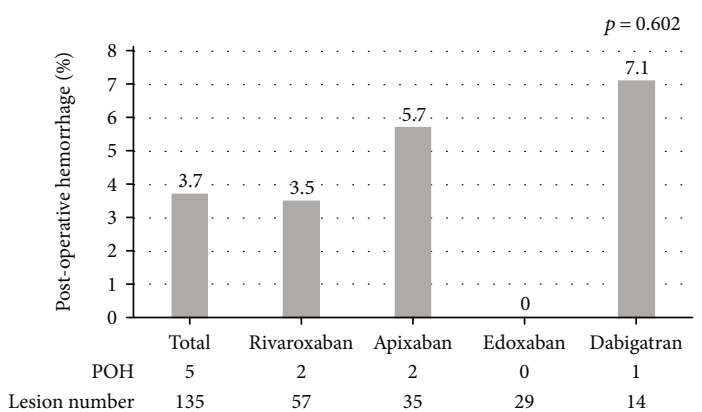

FIgURE 3: The rates of postoperative hemorrhage after endoscopic mucosal resection per lesion by each DOAC.

dent risk factor of $\mathrm{POH}$ after endoscopic submucosal dissection (ESD) for colorectal neoplasia, with an odds ratio of 8.76 (95\% confidence interval:1.24-30.19) [22]. Yamashita et al. also reported that the rate of POH after ESD for colorectal neoplasia in patients receiving anticoagulants (warfarin and DOACs) was higher than in patients not receiving such treatment [23]. Niikura et al. found in their analysis of the nationwide Japan Diagnosis Procedure Combination 


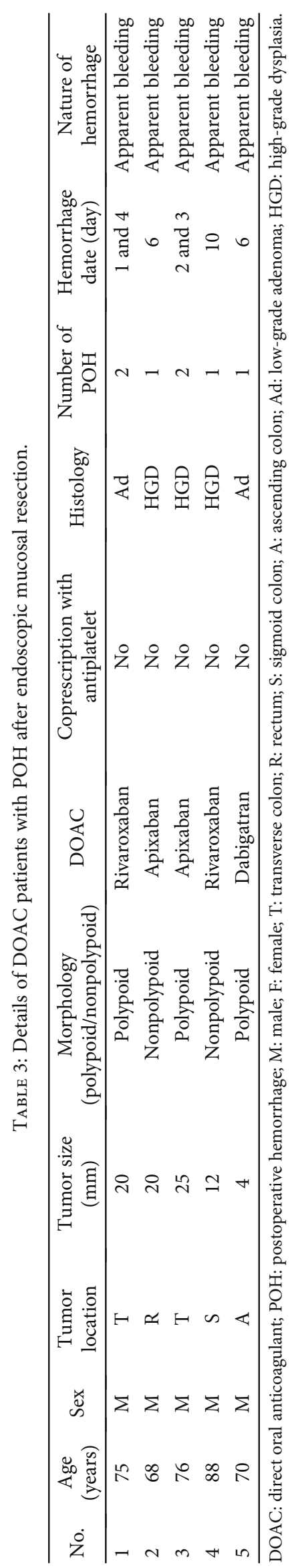




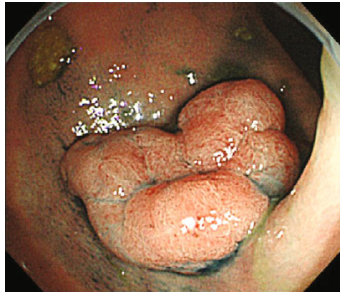

(a)

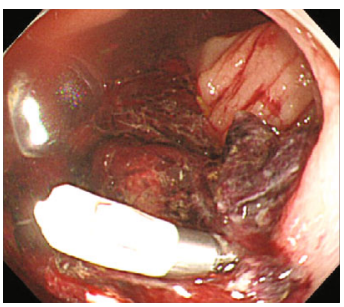

(d)

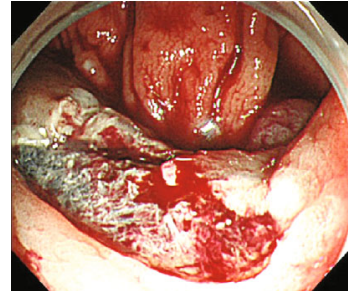

(b)

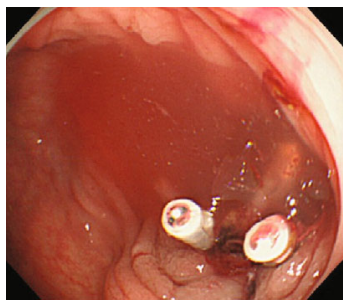

(e)

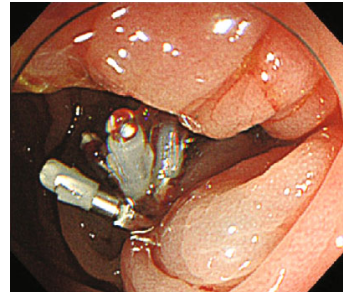

(c)

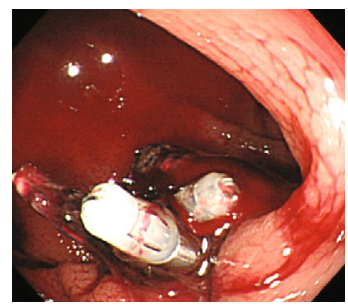

(f)

FIGURE 4: A case treated with DOACs in which postoperative hemorrhage occurred twice after EMR. (a) A 76-year-old man receiving apixaban with no antiplatelets and hemodialysis. A nonpolypoid lesion $25 \mathrm{~mm}$ in size on the transverse colon. (b) EMR was performed. (c) Endoscopic clipping was performed in the EMR ulcer. (d) Postoperative hemorrhage occurred two days after EMR. One previous endoscopic clipping remained in the EMR ulcer. (e) Endoscopic clipping was performed again for hemostasis. (f) Postoperative hemorrhage occurred a second time three days after EMR. Endoscopic clipping was performed again, and no recurrent postoperative hemorrhage occurred after this round of hemostasis.

database that the rate of $\mathrm{POH}$ after therapeutic colonoscopy for colorectal neoplasia in patients receiving DOACs (rivaroxaban, edoxaban, and dabigatran) was significantly higher than that in patients not receiving DOACs. (15.3\% (140/914) vs. $3.2 \%(11102 / 344632), p<0.001)$ [8]. In contrast, Yu et al. reported that patients prescribed DOACs had no significantly increased risk of $\mathrm{POH}$ after EMR, with an odds ratio of 0.90 (95\% confidence interval: 0.44-1.85) after adjusting for clinical background characteristics [24]. Conversely, Yanagisawa et al. reported that, in a retrospective study conducted at a single institution, the rate of $\mathrm{POH}$ after polypectomy for colorectal neoplasia in patients receiving DOACs (rivaroxaban, apixaban, edoxaban, and dabigatran) was significantly higher than that in patients not receiving any antithrombotics $(13.8 \%$ $(10 / 73)$ vs. $0.9 \%(2 / 218), p<0.001)$ [25].

In the present study, we evaluated four types of DOACs and reported for the first time the high rate of $\mathrm{POH}$ about DOAC patients after EMR in a multicenter study.

Previous studies regarding the risk of non-proceduralrelated GI bleeding in DOAC users compared to warfarin have produced varied results, depending on the type of DOAC evaluated. For example, dabigatran at $150 \mathrm{mg}$ twice daily, edoxaban at $60 \mathrm{mg}$ once daily, and rivaroxaban increased non-procedural-related GI bleeding compared to warfarin [26-28]. In contrast, a study showed that apixaban did not increase $\mathrm{POH}$ [29]. In the current study, while the rate of $\mathrm{POH}$ in the DOAC group was higher than that in the warfarin group, this difference did not reach statistical significance probably due to poverty of case number.

Regarding risk factors for $\mathrm{POH}$ besides antithrombotic drugs, several reports have found that the tumor size was a risk factor [30-32]. In the present study, only patients with DOAC were analyzed, and a larger polyp size was found to be a risk factor of $\mathrm{POH}$. Especially, tumor size for $3 \mathrm{POH}$ cases in the DOAC group was $\geq 20 \mathrm{~mm}$. To our knowledge, this is the first report to address risk factors for $\mathrm{POH}$ in patients receiving DOACs.

Regarding the types of DOACs, no significant differences in the rate of $\mathrm{POH}$ after EMR per lesion were noted among DOACs, although none of the patients receiving edoxaban, the most recently developed DOAC, showed POH. Yanagisawa et al. reported that there was no significant difference in the rate of $\mathrm{POH}$ by type of $\mathrm{DOAC}$, but the number of cases was rather small in their study [25]. Regarding dabigatran, it is a prodrug, unlike other DOACs, and remains as a prodrug in the GI tract, there is possibility that dabigatran may be transformed into its active form by intestinal bacteria and thus inhibits hemostasis [33]. Furthermore, dabigatran is the only anticoagulant with a higher ratio of lower GI bleeding than upper GI bleeding [34]. Dabigatran may therefore be associated with a high hemorrhage risk after EMR as well. Further studies are expected for proving the difference of $\mathrm{POH}$ about each DOACs.

Several limitations associated with the present study. This was a retrospective study. Some data such as the polyp size and locations in each group was examined only in cases with detail information from medical records. The materials used-such as the injection solution and snares-as well as the electrosurgical unit settings differed among institutions. The sample size was quite small, although the number of lesions in the DOAC group exceeded 100 cases. The mean age in the no antithrombotics group was significantly younger than that in the other antithrombotics group. This difference in the patient background may have affected the rate of $\mathrm{POH}$. In Japan, lesions $\leq 10 \mathrm{~mm}$ in size were resected by either hot polypectomy or EMR, according to the endoscopist's preference. Recently, most cases have been resected by cold snare polypectomy. In the 8 institutions that participated in this study, endoscopists performed EMR for 
colorectal lesions $<10 \mathrm{~mm}$ in size in order to perform en bloc and $\mathrm{R} 0$ resection.

\section{Conclusion}

Patients receiving DOACs had higher rates of $\mathrm{POH}$ after EMR for colorectal lesions than those not receiving any antithrombotics. A larger tumor size especially tumor size $\geq 20 \mathrm{~mm}$ was a risk factor of $\mathrm{POH}$ in patients with DOACs. The number of DOAC patients is increasing as the elderly population grows. We must be careful when prescribing endoscopic therapy for these patients. The further accumulation of data is needed in order to determine whether or not to extend the discontinuation period of DOACs and to close EMR ulcers endoscopically to prevent $\mathrm{POH}$ in patients receiving DOACs.

\section{Data Availability}

The patient data used to support the findings of this study are available from the corresponding author upon request.

\section{Conflicts of Interest}

All authors have no conflicts of interest to declare.

\section{Acknowledgments}

We thank all of the members of the Department of Molecular Gastroenterology and Hepatology, Kyoto Prefectural University of Medicine, for their assistance with this study.

\section{References}

[1] D. Mozaffarian, E. J. Benjamin, A. S. Go et al., "Heart disease and stroke statistics-2015 update: a report from the American Heart Association," Circulation, vol. 131, no. 4, pp. e29-322, 2015.

[2] S. J. Heitman, P. E. Ronksley, R. J. Hilsden, B. J. Manns, A. Rostom, and B. R. Hemmelgarn, "Prevalence of adenomas and colorectal cancer in average risk individuals: a systematic review and meta-analysis," Clinical Gastroenterology and Hepatology, vol. 7, no. 12, pp. 1272-1278, 2009.

[3] S. R. Puli, Y. Kakugawa, T. Gotoda, D. Antillon, Y. Saito, and M. R. Antillon, "Meta-analysis and systematic review of colorectal endoscopic mucosal resection," World Journal of Gastroenterology, vol. 15, no. 34, pp. 4273-4277, 2009.

[4] M. Matsumoto, S. Yoshii, T. Shigesawa et al., "Safety of Cold Polypectomy for Colorectal Polyps in Patients on Antithrombotic Medication," Digestion, vol. 97, no. 1, pp. 76-81, 2018.

[5] A. E. Burnett, C. E. Mahan, S. R. Vazquez, L. B. Oertel, D. A. Garcia, and J. Ansell, "Guidance for the practical management of the direct oral anticoagulants (DOACs) in VTE treatment," Journal of Thrombosis and Thrombolysis, vol. 41, no. 1, pp. 206-232, 2016.

[6] C. T. Ruff, R. P. Giugliano, E. Braunwald et al., "Comparison of the efficacy and safety of new oral anticoagulants with warfarin in patients with atrial fibrillation: a meta-analysis of randomised trials," Lancet, vol. 383, no. 9921, pp. 955-962, 2014.

[7] R. Niikura, H. Yasunaga, A. Yamada et al., "Factors predicting adverse events associated with therapeutic colonoscopy for colorectal neoplasia: a retrospective nationwide study in Japan," Gastrointestinal Endoscopy, vol. 84, no. 6, pp. 971982.e6, 2016, e6.

[8] K. Mabe, M. Kato, K. Oba et al., "A prospective, multicenter survey on the validity of shorter periendoscopic cessation of antithrombotic agents in Japan," Journal of Gastroenterology, vol. 52, no. 1, pp. 50-60, 2017.

[9] R. D. Acosta, N. S. Abraham, V. Chandrasekhara et al., "The management of antithrombotic agents for patients undergoing GI endoscopy," Gastrointestinal Endoscopy, vol. 83, no. 1, pp. 3-16, 2016.

[10] A. M. Veitch, G. Vanbiervliet, A. H. Gershlick et al., "Endoscopy in patients on antiplatelet or anticoagulant therapy, including direct oral anticoagulants: British Society of Gastroenterology (BSG) and European Society of Gastrointestinal Endoscopy (ESGE) guidelines," Endoscopy, vol. 48, no. 4, pp. 385-402, 2016.

[11] K. Fujimoto, M. Fujishiro, M. Kato et al., "Guidelines for gastroenterological endoscopy in patients undergoing antithrombotic treatment," Digestive Endoscopy, vol. 26, no. 1, pp. 1-14, 2014.

[12] M. Kato, N. Uedo, S. Hokimoto et al., "Guidelines for gastroenterological endoscopy in patients undergoing antithrombotic treatment: 2017 appendix on anticoagulants including direct oral anticoagulants," Digestive Endoscopy, vol. 30, no. 4, pp. 433-440, 2018.

[13] S. Tanaka, H. Kashida, Y. Saito et al., "JGES guidelines for colorectal endoscopic submucosal dissection/endoscopic mucosal resection," Digestive Endoscopy, vol. 27, no. 4, pp. 417-434, 2015.

[14] Participants in the Paris workshop, "The Paris endoscopic classification of superficial neoplastic lesions: esophagus, stomach, and colon: November 30 to December 1, 2002," Gastrointestinal Endoscopy, vol. 58, no. 6, pp. S3-S43, 2003.

[15] Japanese society for cancer of the colon and rectum, Japanese Classification of Colorectal Carcinoma, Kanehara \& Co., Ltd, Tokyo, 8th edition, 2009.

[16] N. Yoshida, Y. Naito, T. Murakami et al., "Safety and efficacy of a same-day low-volume $1 \mathrm{~L}$ PEG bowel preparation in colonoscopy for the elderly people and people with renal dysfunction," Digestive Diseases and Sciences, vol. 61, no. 11, pp. 3229-3235, 2016.

[17] N. Yoshida, Y. Naito, Y. Inada et al., "Endoscopic mucosal resection with $0.13 \%$ hyaluronic acid solution for colorectal polyps less than $20 \mathrm{~mm}$ : a randomized controlled trial," Journal of Gastroenterology and Hepatology, vol. 27, no. 8, pp. 1377-1383, 2012.

[18] M. Singh, N. Mehta, U. K. Murthy, V. Kaul, A. Arif, and N. Newman, "Postpolypectomy bleeding in patients undergoing colonoscopy on uninterrupted clopidogrel therapy," Gastrointestinal Endoscopy, vol. 71, no. 6, pp. 998-1005, 2010.

[19] A. Pan, M. Schlup, R. Lubcke, A. Chou, and M. Schultz, "The role of aspirin in post-polypectomy bleeding-a retrospective survey," BMC Gastroenterology, vol. 12, no. 1, p. 138, 2012.

[20] A. J. Metz, M. J. Bourke, A. Moss, S. J. Williams, M. P. Swan, and K. Byth, "Factors that predict bleeding following endoscopic mucosal resection of large colonic lesions," Endoscopy, vol. 43, no. 6, pp. 506-511, 2011.

[21] A. J. Hui, R. M. Wong, J. Y. Ching, L. C. Hung, S. C. Chung, and J. J. Sung, "Risk of colonoscopic polypectomy bleeding 
with anticoagulants and antiplatelet agents: analysis of 1657 cases," Gastrointestinal Endoscopy, vol. 59, no. 1, pp. 44-48, 2004.

[22] N. Yoshida, Y. Naito, T. Murakami et al., "High incidence of postoperative hemorrhage in colorectal endoscopic submucosal dissection during anticoagulant therapy," International Journal of Colorectal Disease, vol. 31, no. 8, pp. 1487-1488, 2016.

[23] K. Yamashita, S. Oka, S. Tanaka et al., "Use of anticoagulants increases risk of bleeding after colorectal endoscopic submucosal dissection," Endoscopy International Open, vol. 6, no. 7, pp. E857-E864, 2018.

[24] J. X. Yu, M. Oliver, J. Lin et al., "Patients Prescribed DirectActing Oral Anticoagulants Have Low Risk of Postpolypectomy Complications," Clinical Gastroenterology and Hepatology, vol. 17, no. 10, pp. 2000-2007.e3, 2019.

[25] N. Yanagisawa, N. Nagata, K. Watanabe et al., "Post-polypectomy bleeding and thromboembolism risks associated with warfarin $v s$ direct oral anticoagulants," World Journal of Gastroenterology, vol. 24, no. 14, pp. 1540-1549, 2018.

[26] S. J. Connolly, M. D. Ezekowitz, S. Yusuf et al., "Dabigatran versus warfarin in patients with atrial fibrillation," The New England Journal of Medicine, vol. 361, no. 12, pp. 1139-1151, 2009.

[27] R. P. Giugliano, C. T. Ruff, E. Braunwald et al., "Edoxaban versus warfarin in patients with atrial fibrillation," The New England Journal of Medicine, vol. 369, no. 22, pp. 2093-2104, 2013.

[28] M. R. Patel, K. W. Mahaffey, J. Garg et al., "Rivaroxaban versus warfarin in nonvalvular atrial fibrillation," The New England Journal of Medicine, vol. 365, no. 10, pp. 883-891, 2011.

[29] C. B. Granger, J. H. Alexander, J. J. McMurray et al., "Apixaban versus warfarin in patients with atrial fibrillation," The New England Journal of Medicine, vol. 365, no. 11, pp. 981-992, 2011.

[30] M. Conio, A. Repici, J. F. Demarquay, S. Blanchi, R. Dumas, and R. Filiberti, "EMR of large sessile colorectal polyps," Gastrointestinal Endoscopy, vol. 60, no. 2, pp. 234-241, 2004.

[31] N. Arebi, D. Swain, N. Suzuki, C. Fraser, A. Price, and B. P. Saunders, "Endoscopic mucosal resection of 161 cases of large sessile or flat colorectal polyps," Scandinavian Journal of Gastroenterology, vol. 42, no. 7, pp. 859-866, 2007.

[32] C. Luigiano, P. Consolo, M. G. Scaffidi et al., "Endoscopic mucosal resection for large and giant sessile and flat colorectal polyps: a single-center experience with long-term follow-up," Endoscopy, vol. 41, no. 10, pp. 829-835, 2009.

[33] J. Stangier, K. Rathgen, H. Stähle, D. Gansser, and W. Roth, "The pharmacokinetics, pharmacodynamics and tolerability of dabigatran etexilate, a new oral direct thrombin inhibitor, in healthy male subjects," British Journal of Clinical Pharmacology, vol. 64, no. 3, pp. 292-303, 2007.

[34] J. W. Eikelboom, L. Wallentin, S. J. Connolly et al., "Risk of bleeding with 2 doses of dabigatran compared with warfarin in older and younger patients with atrial fibrillation: an analysis of the randomized evaluation of long-term anticoagulant therapy (RE-LY) trial," Circulation, vol. 123, no. 21, pp. 2363-2372, 2011. 


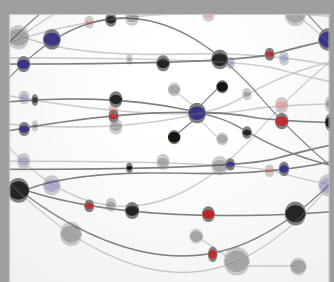

The Scientific World Journal
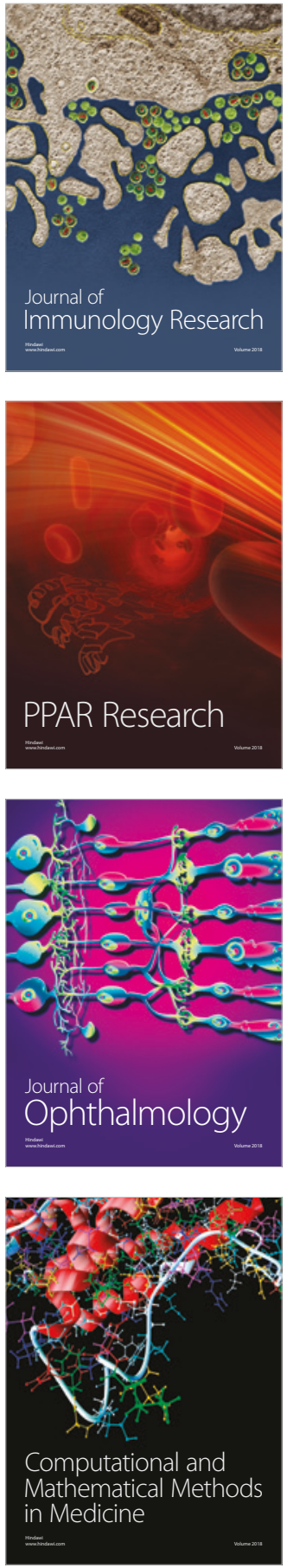

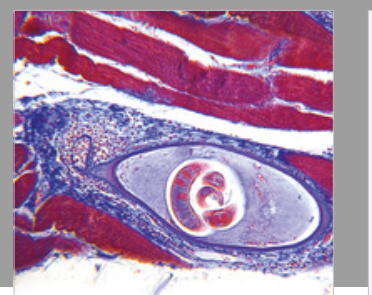

Gastroenterology Research and Practice

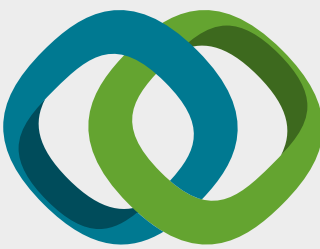

\section{Hindawi}

Submit your manuscripts at

www.hindawi.com
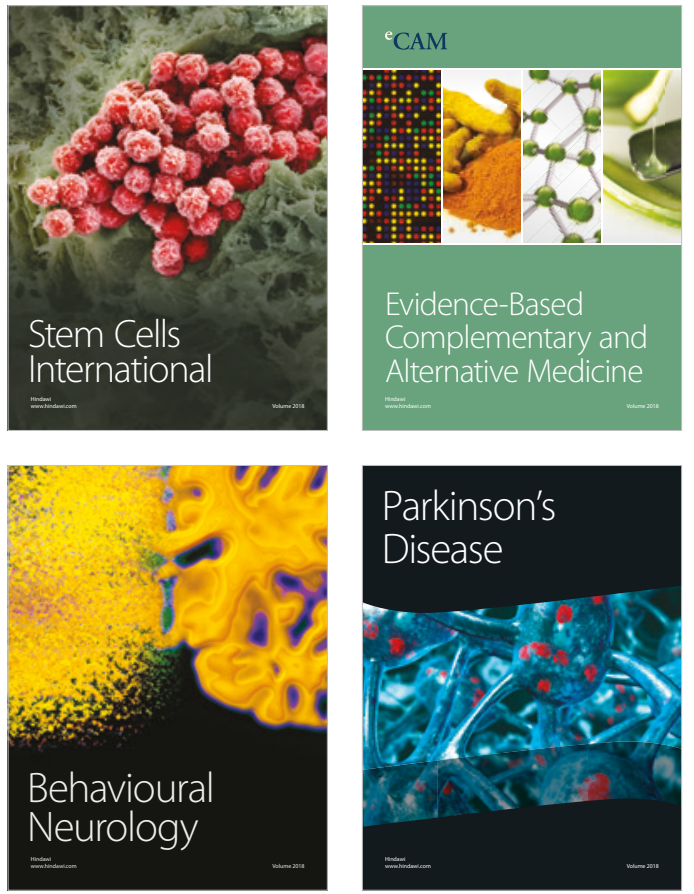

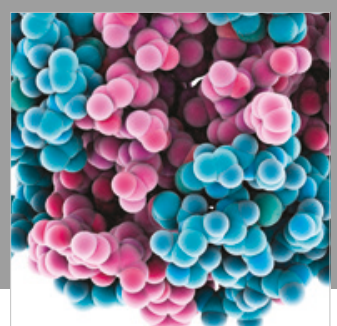

ournal of

Diabetes Research

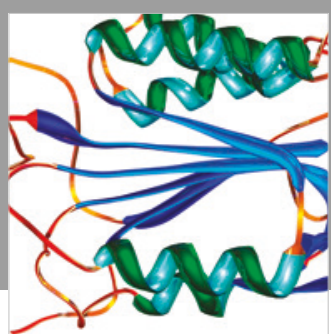

Disease Markers
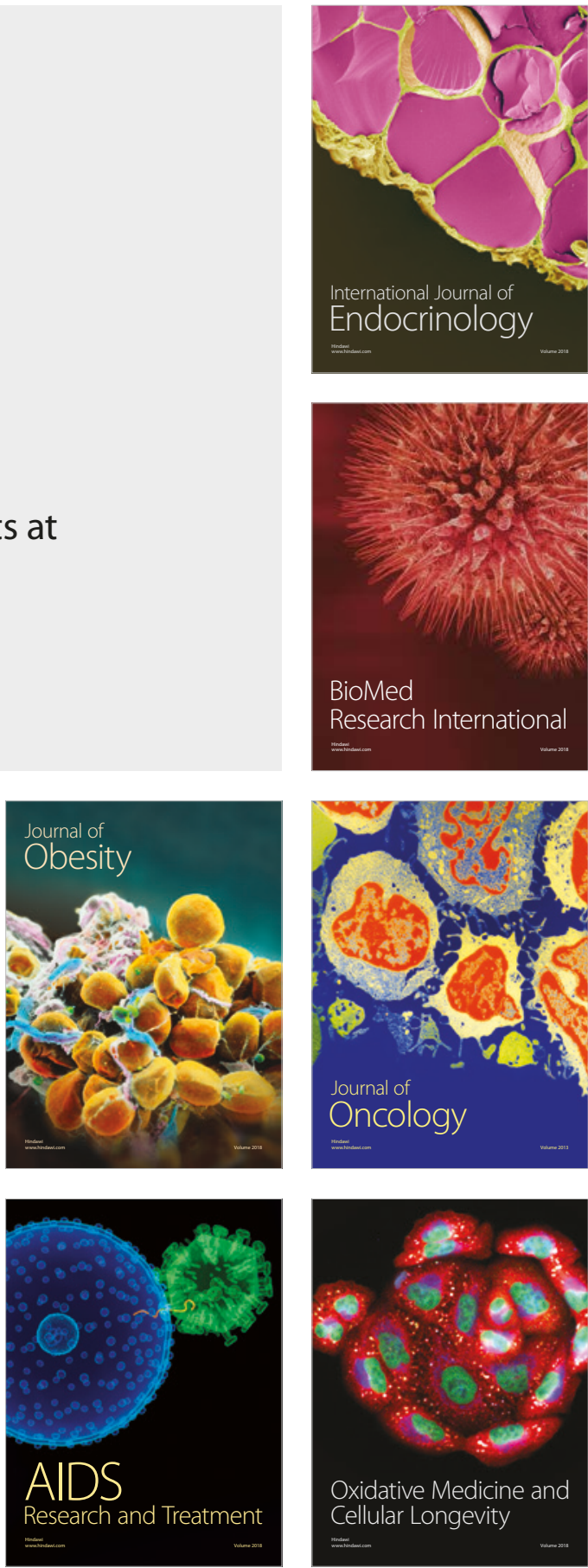